\title{
Rancang Bangun Sistem Keamanan dan Pemantau Tamu pada Pintu Rumah Pintar Berbasis Raspberry Pi dan Chat Bot Telegram
}

\author{
Zaenab Muslimin ${ }^{1 *}$, Muhammad Arief Wicaksono ${ }^{2}$, Muhammad Fandly Fadlurachman ${ }^{2}$, Ilham Ramli ${ }^{1}$ \\ ${ }^{1}$ Departemen Teknik Elektro, Fakultas Teknik, Universitas Hasanuddin \\ ${ }^{2}$ Departemen Teknik Informatika, Fakultas Teknik, Universitas Hasanuddin \\ Jl. Poros Malino km. 6, Bontomarannu, Kabupaten Gowa, Sulawesi Selatan 92171 \\ *Email: zaenabandy@gmail.com
}

DOI: 10.25042/jpe.112019.05

\begin{abstract}
Abstrak
Teknologi saat ini perkembangannya sangat pesat sehingga dapat dipergunakan untuk membantu manusia dalam menjalankan tugas sehari-hari di rumah dengan merancang suatu alat yang dapat dikendalikan dari jarak jauh (remote control) sehingga tercipta rumah idaman dengan peningkatan kenyaman serta keamanan penghuni rumah. Penelitian ini bertujuan merancang sebuah alat untuk memantau tamu yang dilengkapi dengan sistem keamanan dengan menggunakan microprocessor Raspberry Pi untuk memproses data yang akan dikirim ke Chat Bot Telegram. Data yang dikirimkan ke Chat Bot Telegram nantinya akan diakses oleh smartphone berupa gambar tamu yang di ambil oleh kamera raspberry pi. Alat ini memiliki dua mode yaitu mode smart yang digunakan untuk mengambil gambar tamu saat tamu menekan tombol bell dan mode secure yang digunakan untuk mengambil gambar orang yang berada di depan pintu secara otomatis dengan menggunakan sensor PIR. Hasil penelitian menunjukkan bahwa Sensor PIR dengan sensitifitas maksimum dapat mendeteksi objek dengan baik dalam jangkauan jarak maksimum 5 m, Kamera Raspberry Pi dapat mengambil gambar dengan kualitas baik hingga jarak $11 \mathrm{~m}$ dan pengujian pada Chat Bot berjalan dengan baik, seluruh perintah telah di ujicoba dan memberikan informasi dalam bentuk chating yang timbal balik. Prototipe ini memungkinkan pemilik rumah dapat melihat tamu atau orang yang berada di depan pintu melalui smartphone secara real-time.
\end{abstract}

\begin{abstract}
Security Systems and Guest Monitoring Prototypes on Smart Doors Based on Raspberry Pi and Telegram Chat Bot. Current technology is developing so rapidly that it can be used to help people carry out daily tasks at home by designing devices that can be controlled remotely (remote control) so as to create a dream home with increased comfort and safety of residents. This study aims to design a tool for monitoring guests equipped with a security system using the Raspberry Pi microprocessor to process data to be sent to Telegram Chat Bot. Data sent to the Chat Bot Telegram will later be accessed by a smartphone in the form of a guest image taken by a raspberry pi camera. This tool has two modes namely the smart mode that is used to take pictures of guests when a guest presses the bell button and the safe mode is used to take pictures of people who are at the door automatically using a PIR sensor. The results showed that the PIR sensor with maximum sensitivity can detect objects well within a maximum distance of $5 \mathrm{~m}$, the Raspberry Pi camera can take pictures with good quality up to $11 \mathrm{~m}$ distance and testing on the Chat Bot runs well, all commands have been tested and provide information in the form reciprocal chatter. This prototype allows homeowners to see guests or people at the door through a smartphone in real time.
\end{abstract}

Kata Kunci: Chat Bot telegram, Raspberry Pi, sensor PIR, telegram Mesengger

\section{Pendahuluan}

Kriminalitas mengalami peningkatan dari tahun ke tahun khususnya menimpa rumah tangga, misalnya pencurian masih sering terjadi meskipun berfluktuatif. Pencurian terjadi ketika pemilik rumah sedang bepergian dan rumah ditinggal dalam waktu yang cukup lama seperti mudik lebaran ataupun ditinggal ketika penghuni rumah sedang bekerja. Meskipun di beberapa lingkungan perumahan sudah memiliki petugas keamanan, namun keterbatasan manusia dapat menjadi celah bagi pelaku pencurian [1].

Teknologi saat ini berkembang pesat membuat semua alat dapat diciptakan untuk membantu manusia dalam pekerjaannya. Pekerjaan manusia yang dilakukan secara manual seperti penjaga rumah, pada saat sekarang pekerjaan tersebut dapat dilakukan 
dengan hanya melakukan sistem kendali jarak jauh. Penggunaan jaringan internet sebagai media penyaluran sinyal kontrol dan pengendali telah berkembang pesat, salah satu contoh adalah pengendali peralatan dirumah tangga seperti pintu rumah, kontrol peralatan elektronik, dan mesin produksi di industri [2].

Perkembangan teknologi bidang elektronik saat ini sudah sampai pada generasi Internet of Things (IoT). IoT merupakan kumpulan bendabenda (things), berupa perangkat fisik (hardware lembedded system) yang mampu bertukar informasi antar sumber informasi, operator layanan ataupun perangkat lainnya yang terhubung kedalam sistem sehingga dapat memberikan pemanfaatan yang lebih besar. Perangkat fisik (hardwarelembedded system) dalam infrastruktur IoT merupakan hardware yang tertanam (embedded) dengan elektronik, perangkat lunak, sensor dan juga konektivitas. Perangkat embedded system melakukan komputasi untuk pengolahan data dari input sensor dan beroperasi dalam infrastruktur internet. Menurut hasil penelitian dari Juniper Research terdapat pertumbuhan perangkat IoT tiga kali lipat antara tahun 2016 s/d 2021. Menurut hasil penelitian ini perkiraan jumlah peralatan IoT yang terhubung ke internet baik itu device, sensor maupun aktuator mencapai lebih dari 46 billion sampai dengan tahun 2021 [3].

Penelitian ini memanfaatkan teknologi IoT, yaitu bagaimana Internet of Things mampu melakukan monitoring rumah dari jarak jauh dengan memanfaatkan aplikasi telegram messenger. Penggunaan telegram messenger pada penelitian ini adalah karena sifatnya yang open source. Kelebihan tersebut membuat pengguna dapat melihat source code, protocol dan Application Program Interface (API) yang ada di dalamnya. Hal ini memudahkan pengguna ketika ingin membuat aplikasi tambahan seperti pada penelitian ini. Telegram Messenger merupakan Instant Messenger platform yang mendukung operating system (OS) berbasis Linux sehingga kompatibel dengan Raspberry Pi yang juga menggunakan OS yang sama [1]. Fitur Chat Bot yang tidak ada pada instant messenger menjadi kelebihan lainnya. Chat Bot adalah akun penjawab otomatis yang dapat merespon teks tertentu sesuai dengan perintah yang kita berikan. Sistem keamanan ini memanfaatkan sensor PIR yang dapat mendeteksi adanya gerakan manusia. Jika sensor aktif, maka akan memicu kamera yang terhubung pada Raspberry Pi untuk mengambil foto dan mengirimkan gambar tersebut kepada pemilik rumah melalui aplikasi Telegram Messenger.

\section{Tinjauan Pustaka}

Penggunaan komputer dimasa mendatang mampu mendominasi pekerjaan manusia dan mengalahkan kemampuan komputasi manusia seperti mengontrol peralatan elektronik dari jarak jauh menggunakan media internet, IoT memungkinkan pengguna untuk mengelola dan mengoptimalkan elektronik dan peralatan listrik yang menggunakan internet [4]. IoT merupakan sebuah konsep yang bertujuan untuk memperluas manfaat dari konektivitas internet yang tersambung secara terus-menerus. Adapun penggunaannya seperti berbagi data, kontrol jarak jauh, dan sebagainya, termasuk benda hidup yang semuanya tersambung ke jaringan lokal dan global melalui sensor yang tertanam dan selalu aktif.

\subsection{Raspberry Pi}

Raspberry Pi adalah modul mikro komputer yg juga mempunyai input output digital port seperti pada board microcontroller. Diantara kelebihan Rasberry $\mathrm{Pi}$ dibanding board microcontroller yaitu mempunyai port/koneksi untuk display berupa TV atau Monitor PC serta koneksi USB untuk keyboard serta mouse.

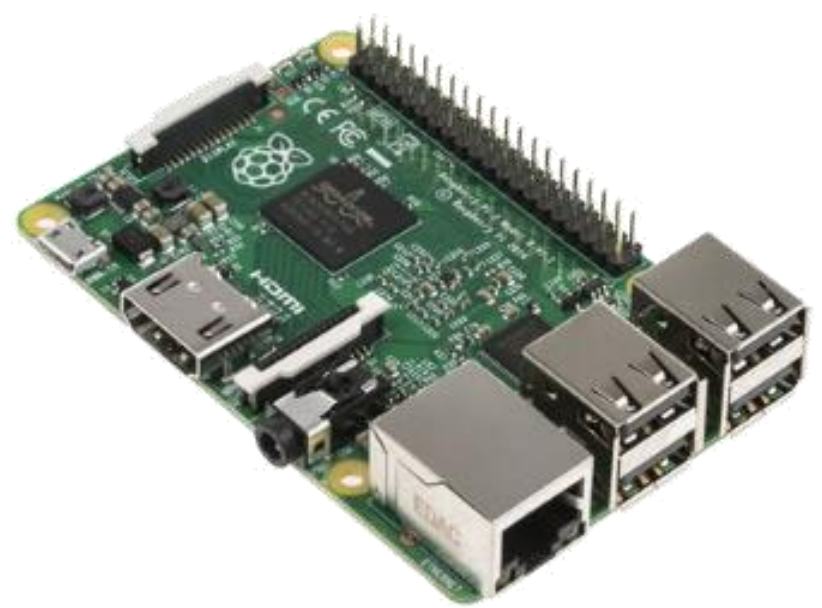

Gambar 1. Microprocessor Raspberry pi 3B+

Raspberry Pi board dibuat dengan type yang berbeda yaitu Raspberry $\mathrm{Pi}$ type $\mathrm{A}, \mathrm{A}+$ Raspberry Pi type B, B+ Raspberry pi 2, 
Rasberry pi 3 Raspberry Pi zero. Perbedaannya antara lain pada Ram dan Port LAN. Type A $\mathrm{RAM}=256 \mathrm{MB}$ dan tanpa port LAN(ethernet), type $\mathrm{B}=512 \mathrm{MB}$ dan terpasang port untuk LAN. Raspberry $\mathrm{Pi}$ yang digunaakan pada penelitian ini merupakan Raspberry $\mathrm{Pi}$ versi $3 \mathrm{~B}+$ yang dapat dilihat pada Gambar $1[5$, $6]$.

\subsection{Modul Kamera Raspberry Pi 5MP}

Modul kamera yang didesain khusus untuk Raspberry Pi ini mampu memberikan gambar jernih berukuran 5MP atau merekam video 1080 pHD dengan kecepatan 30fps. Modul ini melekat pada Raspberry Pi dengan menggunakan kabel pita 15 Pin ke 15 pin MIPI Camera Serial Interface (CSI) yang dirancang khusus untuk antarmuka modul kamera. CSI Bus mampu mengirim data dengan kecepatan yang sangat tinggi dan secara eksklusif membawa data piksel ke prosesor BCM2835 [7].

\subsection{Sensor Passive Infra Red (PIR)}

Sensor Passive Infra Red (PIR) biasanya digunakan dalam perancangan detektor gerakan berbasis PIR. Karena semua benda memancarkan energi radiasi, sebuah gerakan akan terdeteksi ketika sumber infra merah dengan suhu tertentu (misal: manusia) melewati sumber infra merah yang lain dengan suhu yang berbeda (misal: dinding), maka sensor akan membandingkan pancaran infra merah yang diterima setiap satuan waktu, sehingga jika ada pergerakan maka akan terjadi perubahan pembacaan pada sensor [8].

Cara kerjanya adalah pancaran infra merah masuk melalui lensa fresnel dan mengenai sensor pyroelektrik, karena sinar infra merah mengandung energi panas maka sensor pyroelektrik akan menghasilkan arus listrik. Arus listrik inilah yang akan menimbulkan tegangan dan dibaca secara analog oleh sensor. Kemudian sinyal ini akan dikuatkan oleh penguat dan dibandingkan oleh komparator dengan tegangan referensi tertentu (keluaran berupa sinyal 1-bit). Jadi sensor PIR hanya akan mengeluarkan logika 0 dan 1,0 saat sensor tidak mendeteksi adanya perubahan pancaran infra merah dan 1 saat sensor mendeteksi infra merah. Sensor PIR didesain dan dirancang hanya mendeteksi pancaran infra merah dengan panjang gelombang 8-14 mikrometer. Diluar panjang gelombang tersebut sensor tidak akan mendeteksinya. Untuk manusia sendiri memiliki suhu badan yang dapat menghasilkan pancaran infra merah dengan panjang gelombang antara 9-10 mikrometer (nilai standar 9,4 mikrometer), panjang gelombang tersebut dapat terdeteksi oleh sensor PIR. (Secara umum sensor PIR dirancang untuk mendeteksi infra merah tubuh manusia) [9].

\subsection{Solenoid Door Lock}

Solenoid Door Lock adalah salah satu solenoid pengunci otomatis yang difungsikan khusus sebagai solenoid untuk pengunci pintu. Solenoid Door Lock ini membutuhkan tegangan supply $12 \mathrm{v}$, sistem kerja solenoid pengunci pintu ini adalah NC (Normally Close). Katup solenoid akan tertarik jika ada tegangan dan sebaliknya katup solenoid akan memanjang jika tidak ada tegangan [10].

\subsection{Telegram}

Telegram adalah sebuah aplikasi layanan pengirim pesan instan multiplatform berbasis awan yang bersifat gratis dan nirlaba. Klien Telegram tersedia untuk perangkat telepon seluler (Android, iOS, Windows Phone, Ubuntu Touch) dan sistem perangkat komputer (Windows, OS X, Linux). Para pengguna dapat mengirim pesan dan bertukar foto, video, stiker, audio, dan tipe berkas lainnya. Telegram juga menyediakan pengiriman pesan ujung ke ujung terenkripsi opsional. Kode pihak kliennya berupa perangkat lunak sistem terbuka namun mengandung blob binari, dan kode sumber untuk versi terbaru tidak selalu segera dipublikasikan, sedangkan kode sisi servernya bersumber tertutup dan berpaten. Layanan ini juga menyediakan API kepada pengembang independen [11].

\section{Perancangan dan Pembuatan Sistem}

Perancangan dan pembuatan sistem dibedakan atas dua perancangan yaitu perancangan perangkat keras (hardware) dan perancangan perangkat lunak (software). Gambar 2 menunjukkan flowchart atau diagram alir perancangan sistem tersebut. Alur kerja dari sistem tersebut dimulai dari pengecekan apakah user mengirimkan perintah untuk menerima input dari tombol atau tidak. Ketika tamu atau 
seseorang datang dan menekan tombol, buzzer akan berbunyi satu kali dan secara bersamaan program akan mengambil gambar kemudian menyimpan di SD Card dan secara otomatis mengirimkan pemberitahuan ke user melalui Chat Bot Telegram beserta gambar dari tamu atau seseorang tersebut. Sedangkan jika user mengirimkan perintah untuk mengaktifkan sensor PIR, maka kamera akan standby untuk mengambil gambar jika gerakan terdeteksi, dan secara bersamaan mengirimkan pemberitahuan serta gambar ke user melalui Chat Bot.

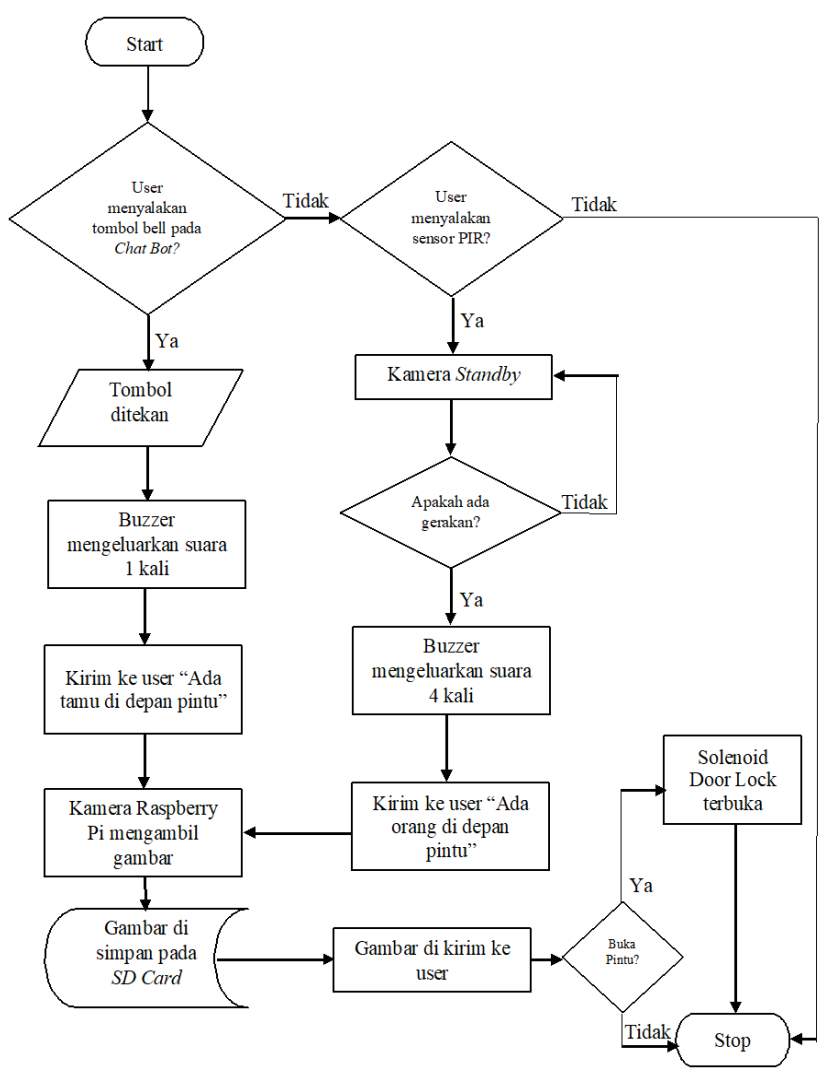

Gambar 2. Diagram alir perancangan sistem secara umum

Pada prinsipnya alat ini menggunakan sensor PIR yang digunakan untuk mendeteksi adanya gerakan, kamera raspberry pi yang berfungsi mengambil gambar ketika seseorang atau tamu berada didepan pintu rumah dan solenoid door lock sebagai pengunci pintu yang dapat dikendalikan. Komponen-kompenen tersebut kemudian dihubungkan dengan raspberry pi. Gambar dan informasi kemudian akan dikirim ke smartphone dalam bentuk chat melalui aplikasi telegram, blok diagram sistem seperti pada Gambar 3.

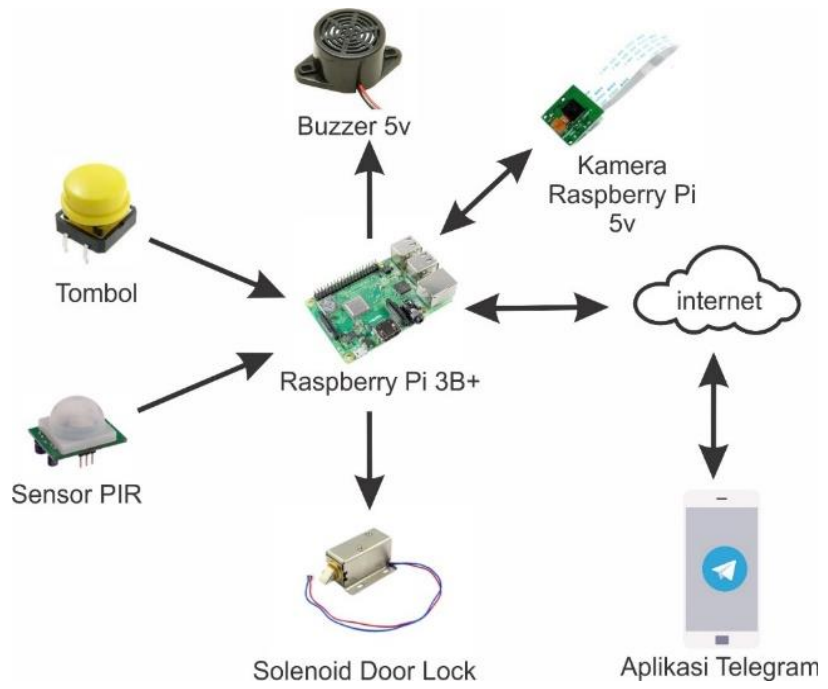

Gambar 3. Blok diagram sistem

\subsection{Perancangan Perangkat Keras}

Perancangan perangkat keras meliputi perancangan prototipe pintu dan perancangan rangkaian sistem. Pada Gambar 4 tampak rangkaian sistem yang dibuat dengan perangkat lunak Fritzing, perangkat lunak ini berfungi untuk membuat simulasi rangkaian sebelum direalisasikan. Fritzing juga memungkinkan untuk melihat schematic dari rangkaian yang dibuat jika ingin di terapkan pada papan PCB.

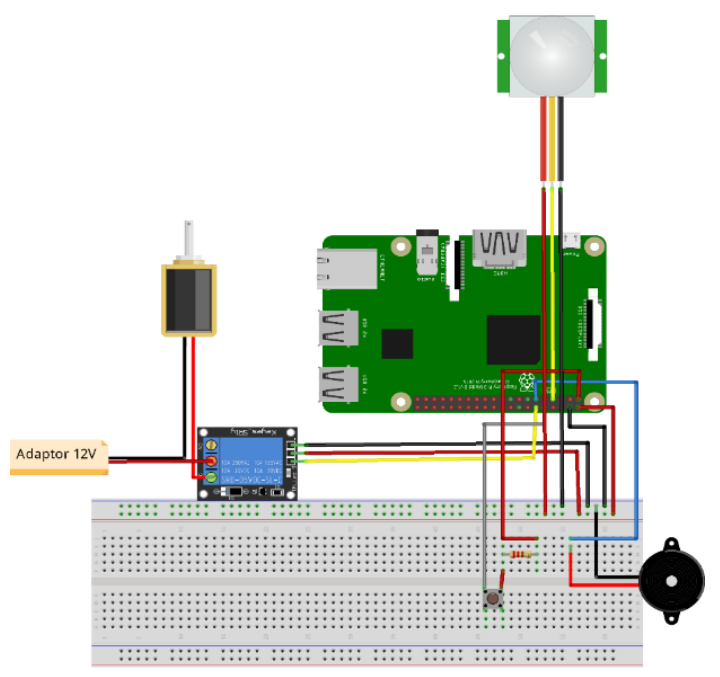

Gambar 4. Skema sistem deteksi tamu

Gambar 5 adalah pemasangan rangkaian pada prototipe pintu. 


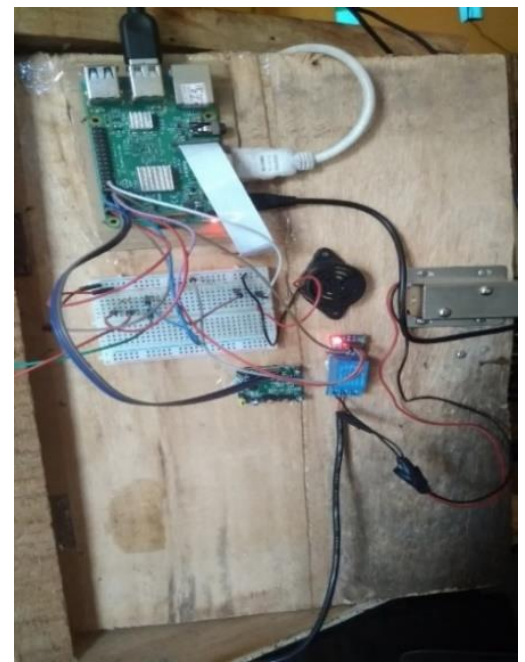

Gambar 5. Skema sistem deteksi tamu

\subsection{Perancangan Perangkat Lunak}

Perancangan perangkat lunak dimulai dengan membuat program dalam bahasa Python. Program Bahasa Python yang dijalankan akan mengakses server telegram dan mencocokkan API (Application Programming Interface) pada program dengan API pada Chat Bot yang telah dibuat API ((Application Programming Interface) yang di hasilkan oleh BotFather untuk mengakses Chat Bot. Jika progam berjalan dengan sempurna maka bot akan mengeksekusi kode program tanpa ada masalah seperti pada Gambar 6 .

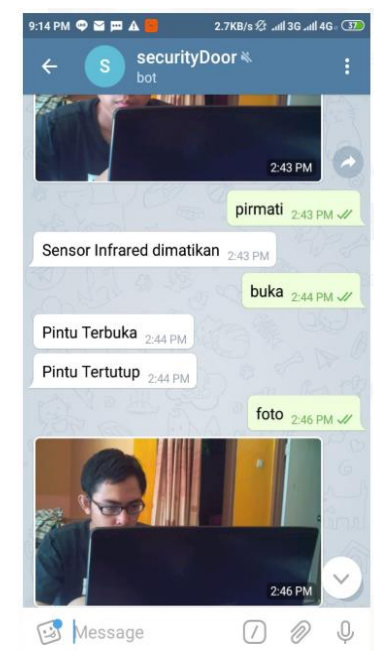

Gambar 6. Chat Bot mengirim gambar ke user

\section{Hasil Pengujian dan Pembahasan}

\subsection{Pengujian Sensor PIR}

Untuk mendeteksi adanya gerakan di depan pintu digunakan sensor PIR dengan sensitifitas maksimum. Prototipe di letakkan pada pintu menghadap ke arah luar. Objek yang akan di deteksi oleh sensor PIR adalah gerakann manusia. Pengujian dilakukan terhadap objek dari prototipe dimulai pada jarak $1 \mathrm{~m}$, adapun hasilnya dapat dilihat pada Tabel 1 .

Tabel 1. Hasil pengujian sensor PIR terhadap objek

\begin{tabular}{ccc}
\hline Objek & Jarak $(\mathbf{m})$ & Respon \\
\hline & 1 & Aktif \\
& 2 & Aktif \\
Manusia & 3 & Aktif \\
& 4 & Aktif \\
& 5 & Aktif \\
& 6 & Tidak Aktif \\
\hline
\end{tabular}

Berdasarkan Tabel 1, terlihat bahwa sensor PIR yang digunakan pada penelitian ini dapat mendeteksi keberadaan objek (manusia) maksimum $5 \mathrm{~m}$ jika ditarik lurus ke depan sensor. Namun saat objek berada pada jarak 6 $\mathrm{m}$, sensor PIR sudah tidak dapat mendeteksi keberadaan objek.

\subsection{Pengujian Kamera Raspberry Pi}

Kamera yang digunakan pada penelitian ini merupakan kamera Raspberry Pi dengan resolusi sebesar 5MP. Prototipe diletakkan pada ketinggian $160 \mathrm{~cm}$ dengan asumsi rata-rata tinggi orang Indonesia. Pengujian dilakukan pada objek dengan mengambil jarak objek dari prototipe mulai $1 \mathrm{~m}$ pada pagi hari yang cerah, adapun hasilnya dapat dilihat pada Gambar 7 dan Tabel 2.

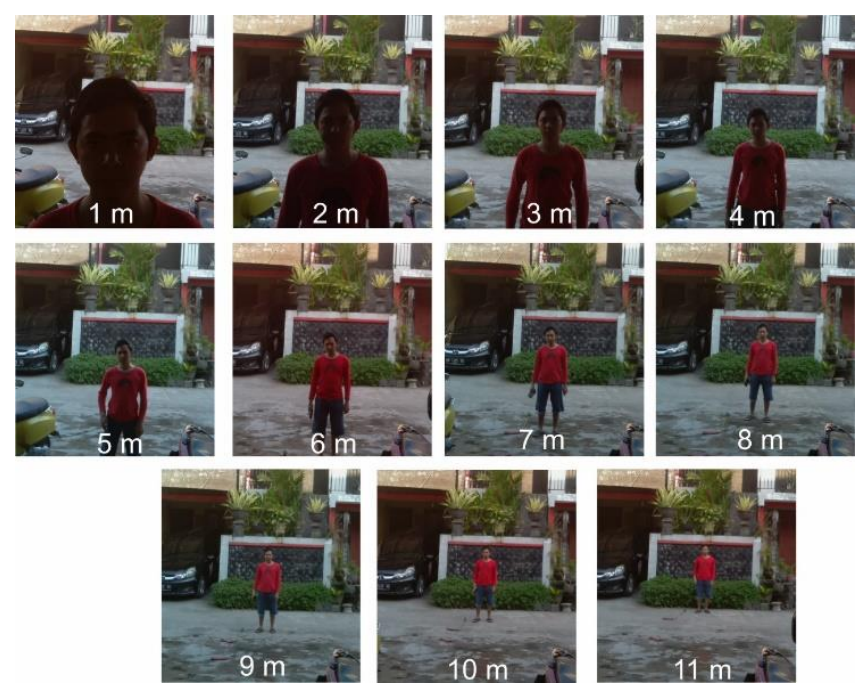

Gambar 7. Pengujian pengambilan gambar

Berdasarkan Gambar 7 dan Tabel 2, terlihat bahwa kamera Raspberry Pi dapat mengambil 
gambar dengan kualitas baik dan wajah objek masih dapat dikenali hingga pada jarak $11 \mathrm{~m}$.

Tabel 2. Hasil pengujian kamera Raspberry Pi

\begin{tabular}{cc}
\hline $\begin{array}{c}\text { Jarak } \\
(\mathbf{m})\end{array}$ & Terlihat kamera \\
\hline 1 & $\mathrm{Ya}$ \\
2 & $\mathrm{Ya}$ \\
3 & $\mathrm{Ya}$ \\
4 & $\mathrm{Ya}$ \\
5 & $\mathrm{Ya}$ \\
6 & $\mathrm{Ya}$ \\
7 & $\mathrm{Ya}$ \\
8 & $\mathrm{Ya}$ \\
9 & $\mathrm{Ya}$ \\
10 & $\mathrm{Ya}$ \\
11 & $\mathrm{Ya}$ \\
\hline
\end{tabular}

\subsection{Pengujian Perintah Chat Bot Telegram}

- Perintah "bell"

Perintah ini digunakan untuk mengaktifkan mode "smart" dan memberi akses kepada tombol untuk membunyikan buzzer dan mengambil gambar. Perintah ini diuji coba dengan mengirim perintah "bell" ke Chat Bot dan menerima pemberitahuan bahwa "bell dapat ditekan" lalu tombol bell pada prototipe pintu ditekan seperti yang terlihat pada Gambar 8 . Hasil yang diperoleh bahwa program berjalan dengan baik dan gambar yang dihasilkan berukuran sekitar $477 \mathrm{~kb}$ dengan resolusi $1280 \mathrm{x}$ 720 pixel. Namun terdapat delay sekitar kurang lebih 20 detik, lama delay ini bergantung dari kecepatan internet yang digunakan pada Raspberry Pi serta smartphone.

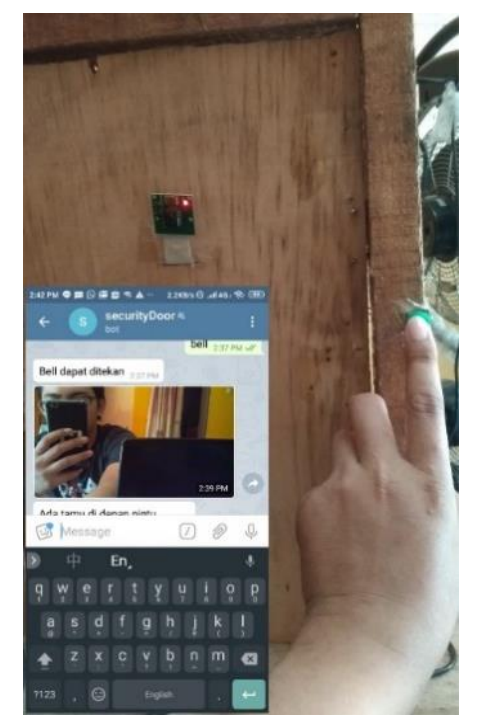

Gambar 8. Pengujian tombol bell
- Perintah "pirnyala" \& "pirmati"

Perintah ini digunakan untuk mengaktifkan mode "secure" dan menyalakan sensor PIR serta mengakses kamera dalam mode standby. Sensor PIR akan mendeteksi keberadaan seseorang didepan pintu melalui suhu tubuh seseorang, maka sensor PIR akan membunyikan buzzer dan mengambil gambar serta mengirimkan pemberitahuan "ada orang di depan pintu". Gambar yang diperoleh akan dikirim ke Chat Bot Telegram seperti pada Gambar 9, dan pengguna dapat mengirimkan perintah "pirmati" untuk mematikan mode "secure" agar sensor tidak mendeteksi pergerakan secara terus menerus.

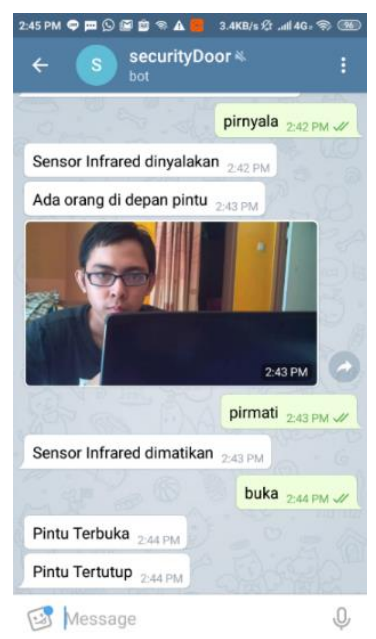

Gambar 9. Pengujian perintah "pirnyala", "pirmati”, dan "buka" pada Chat Bot

- Perintah "buka"

Perintah "buka" digunakan untuk membuka pintu dengan mengirimkan perintah kepada Raspberry Pi untuk mengontrol Solenoid Door Lock. Ketika pengguna mengirimkan perintah "buka" ke Chat Bot, maka sesaat kemudian pengguna akan menerima pemberitahuan "Pintu Terbuka" dari Chat Bot dan secara otomatis Solenoid Door Lock akan terbuka seperti terlihat pada Gambar 10.
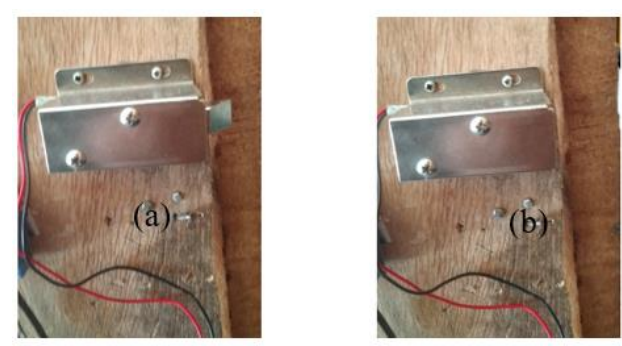

Gambar 10. Solenoid door lock (a) tertutup (b) terbuka 
Setelah 5 detik maka Solenoid Door Lock akan tertutup secara otomatis dan memberikan pemberitahuan kepada pengguna "Pintu Tertutup".

\section{- Perintah "foto' dan "/list"}

Perintah "foto" fungsinya untuk mengambil gambar menggunakan kamera Raspberry Pi dan mengirimkannya ke Chat Bot Telegram, fungsi dari perintah ini agar pengguna dapat melihat keadaan di depan pintu sedangkan perintah "/list" berfungsi untuk menampilkan perintah apa saja yang dapat digunakan pada Chat Bot seperti yang terlihat pada Gambar 11 .

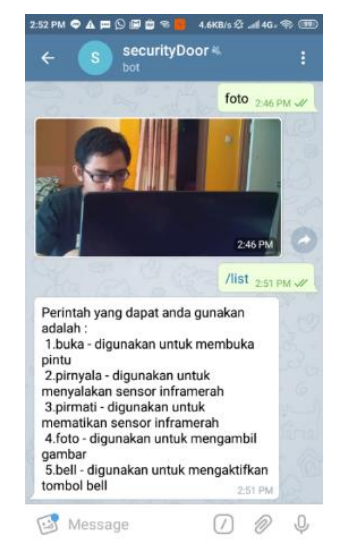

\section{Gambar 11. Pengujian perintah "foto" dan "/list" pada Chat Bot}

Jika pengguna mengirim perintah yang tidak terdapat pada list perintah yang tersedia, maka program akan mengirimkan pemberitahuan kepada pengguna "Maaf, Perintah yang anda masukkan salah" seperti pada Gambar 12.

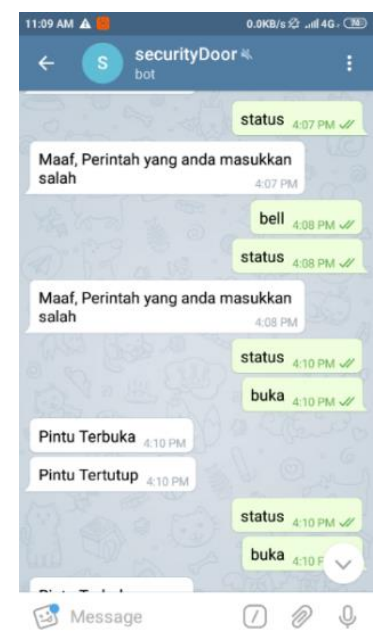

Gambar 12. Pengujian perintah random

\section{Kesimpulan}

Sensor PIR dengan sensitifitas maksimum dapat mendeteksi objek dengan baik dalam jangkauan jarak maksimum $5 \mathrm{~m}$ dan kamera Raspberry Pi dapat mengambil gambar dengan kualitas baik dengan wajah objek masih dapat dikenali hingga jarak $11 \mathrm{~m}$. Perintah Chat Bot berjalan dengan baik, berdasarkan hasil pengujian seluruh perintah memberikan informasi dalam bentuk chating yang timbal balik dan perintah yang dikirimkan oleh pengguna melalaui chat bot dapat diterima oleh raspberry pi dalam waktu $<1$ detik sehingga sistem ini dapat digunakan untuk memonitoring tamu secara real time.

\section{Referensi}

[1] Muhamad Irfan Kurniawan, Unang Sunarya, Rohmat Tulloh; Internet of Things: Sistem Keamanan Rumah berbasis Raspberry Pi dan Telegram Messenger; TELKOMIKA, Vol. 6, No. 1, Hal. 1 - 15; 1 Januari 2018.

[2] Marliana Sari, Protype Pengamanan Pintu Dengan Menggunakan Android Dan Embedded Sistem Nirkabel, Jurnal Ilmiah FIFO; Volume VII, No. 1 Mei 2015.

[3] Muhammad Izzuddin Mahali, Smart Door Locks Based On Internet of Things Concept with Mobile Backend as a Service; Jurnal Electronics, Informatics, and Vocational Education (ELINVO), Volume 1, Nomor 3, November 2016.

[4] Apri Junaidi, Internet of Things, Sejarah, Teknologi Dan Penerapannya: Review; Jurnal Ilmiah Teknologi Informasi Terapan (JITTER), Volume I, No 3, 10 Agustus 2015.

[5] Andi Dinata 2017: Physical Computing dengan Raspberry Pi, Kompas Gramedia, Penerbit PT. Elex Media Komputindo.

[6] Mardhan Ramli, Dringhuzen J. Mamahit, Janny O. Wuwung; Rancang Bangun Sistem Pemantau Tamu Pada Smart Home Berbasis Raspberry PI 3; Ejournal Teknik Elektro dan Komputer Vol. 7 no. 1 2018.

[7] Nareshkumar R. M., Apoorva Kamat, Dnyaneshvari Shinde; Smart Door Security Control System Using Raspberry Pi; International Journal of Innovations \& Advancement in Computer Science (IJIACS), Volume 6, Issue 11 November 2017.

[8] Jacquline Waworundeng, Lazarus D. Irawan, Calvin Alan P; Implementasi Sensor PIR sebagai Pendeteksi Gerakan untuk Sistem Keamanan Rumah menggunakan Platform IoT; Cogito Smart Journal, Vol.3, No.2, Des 2018.

[9] Edi Putra Dewa, Rikie Kartadie; Integrasi Sensor Gerak Dan Ponsel Pada Arduino Sebagai Sistem Kontrol Keamanan Rumah; JIPI (Jurnal Ilmiah Penelitian dan Pembelajaran Informatika) Volume 01, Nomor 02, Desember: 30 - 37. 
[10] Atikah Hazarah; Rancang Bangun Smart Door Lock Menggunakan Qr Code Dan Solenoid; Jurnal Teknologi Informatika dan Terapan Vol. 04, No 01, Januari - Juni 2017.
[11]Gde Sastrawangsa; Pemanfaatan Telegram Bot Untuk Automatisasi Layanan Dan Informasi Mahasiswa Dalam Konsep Smart; Konferensi Nasional Sistem \& Informatika 2017; STMIK STIKOM Bali, 10 Agustus 2017. 